\title{
Cavity Preparation with Er:YAG Laser or Rotary Instruments: Investigation of the Composite Resin Restorations Interface
}

\author{
${ }^{1}$ Carlos Rocha Gomes Torres, ${ }^{2}$ Maria Amélia Máximo de Araujo, ${ }^{3}$ Simone Cristina Teixeira \\ ${ }^{4}$ Rodrigo Máximo de Araújo, ${ }^{1}$ Maria Filomena Rocha Lima Huhtala \\ ${ }^{1}$ Associate Professor, Department of Restorative Dentistry, UNESP—São José Dos Campos Dental School, São Paulo, Brazil \\ ${ }^{2}$ Chairman and Professor, Department of Restorative Dentistry, UNESP—São José Dos Campos Dental School, São Paulo, Brazil \\ ${ }^{3}$ Associate Professor, Department of Social Science and Pediatric Dentistry, UNESP_São José Dos Campos Dental School, São Paulo, Brazil \\ ${ }^{4}$ Associate Professor, Department of Dental Materials and Prosthodontics, UNESP_São José Dos Campos Dental School, São Paulo, Brazil
}

Correspondence: Carlos Rocha Gomes Torres, Av Eng Francisco José Longo, 777, Jardim São Dimas, São José dos Campos São Paulo, CEP 12245-000, Brazil, e-mail: carlosrgt@ fosjc.unesp.br

\begin{abstract}
This study evaluated the sealing of composite resin restorations after cavity preparation with high speed diamonds burs or Er:YAG laser. Two different adhesive systems were used; conventional and self-etching. Seventy bovine incisors were divided into groups according to the cavity treatment ( $N=10)$ : G1 (bur + acid + Excite); G2 (bur + One Up); G3 (bur + laser + Excite); G3 (bur + laser + One Up); G4 (laser + acid + Excite); G5 (laser + One Up) and G6 (laser + Excite). Restorations were performed with Filtek Z250 3M/ESPE. The specimes were then thermocycled and placed in a vacuum machine, at a negative atmosphere of $20 \mathrm{inch} \mathrm{Hg}$ for 5 minutes, for removal of entrapped air. This procedure was followed by immersion in a $50 \%$ silver nitrate solution. The teeth were sectioned and the evaluation of the marginal leakage was performed in a light stereomicroscope. The results were submitted to the ANOVA and Tukey statistical tests. It was concluded that preparations performed with high-speed turbines and Er:YAG laser presented the same performance; preparations with Er:YAG laser submitted to acid-etching and conventional adhesive system presented high values of marginal leakage, with statistical significance; conventional and self-etching adhesive systems presented the same performance as to marginal microleakage.

Keywords: Laser Er:YAG, Dentin adhesives, Microleakage.
\end{abstract}

\section{INTRODUCTION}

Recently, the attention to the adhesive systems has been addressing the easy application and reduced time required for the procedure. However, contradictory outcomes have been presented in the literature on studies on the effectiveness of marginal sealing provided by multistep adhesive systems, based on the concepts of total acid-etching and humid adhesion compared to the self-etching adhesive systems. ${ }^{1}$

Besides the search for adhesive materials that may allow perfect marginal sealing, dentistry has been investigating alternative equipments to the conventional rotary instrument that may not only cut the tooth structure but also allow more conservative cavity preparations with more comfort to the patient during the procedure. These new alternatives include equipments of laser irradiation, more specifically the Er:YAG laser. $^{2-6}$

The Er:YAG laser (erbium: yttrium-aluminum-garnet) with wavelength of $2.94 \mathrm{~mm}$ coincides with the maximum spectrum of water and hydroxyapatite absorption, consequently with maximum absorption, i.e. transformation of thermal energy, and minimum refraction, which represents minimum penetration into the dental tissue, with no underlying heating, since all radiation is resorbed by the water surface. This mechanism of removal of the hard tissue, associated to its characteristic of pulsatile laser and short period of application, limits the thermal load on the tissue..$^{2,4-6}$

The Er:YAG laser has been demonstrated to be effective for removal of dental tissue and provide comfort to the patient. ${ }^{3}$ The performance of adhesive materials on the tooth surfaces achieved after utilization of this appliance is not yet well established, since these surfaces are different from those produced by rotary instruments on which these materials are commonly applied, and evaluation of the bonding interface reveals contradictory outcomes. ${ }^{4-6}$

With the utilization of laser, there will be a new dentin substrate, which brings about doubts on its ability to interact with the existing adhesive materials. This encouraged the present study, which evaluated the sealing of composite resin restorations performed after cavity preparation with Er:YAG laser or highspeed turbine, either prepared with Er:YAG laser or following the instructions of the conventional or self-etching adhesives.

\section{MATERIALS AND METHODS}

Seventy bovine incisors were used for the marginal microleakage test. The teeth were intact and erupted, and were achieved from animals with a mean age of 3 years. They were extracted immediately after slaughtering, cleaned with a blade and polished 
with pumice, water and a rotary brush. Then they were analyzed in a stereomicroscope (Stemi 2000-C, Carl Zeiss Jena) and the teeth selected were sectioned with a carborundum disk at highspeed lathe (Nevoni). The pulp tissue was removed with Kerr files via the apex, and the pulp chamber was irrigated with distilled water. Until utilization, the teeth were immersed in distilled water and kept in a freezer at $18^{\circ} \mathrm{C} .{ }^{7}$ Before preparation of the cavities, the teeth were placed in a silicone mold for embedding, and part of the root was embedded in acrylic resin for achievement of a proper base for fixation.

The specimens were divided into two groups:

Group 1 (40 teeth) - a specific device for cavity preparations was used, which comprised a high-speed turbine connected to a microscope base modified for standardization of the cavity preparations, with $3 \mathrm{~mm}$ in mesiodistal direction, $3 \mathrm{~mm}$ in incisal-apical direction and $1.5 \mathrm{~mm}$ in depth, at the cementoenamel limit. Diamond burs no. 1090 were used under thorough cooling and were replaced at every five preparations.

Group2-with a view to achieve cavity dimensions as those of group 1, an adhesive tape was placed on the tooth surface (sealer tape - Metalúrgica Barlei) with a standardized perforation similar to the dimensions of the preparations performed in group 1. The Er:YAG laser - Kavo III, of high energy and wavelength of $2.94 \mu \mathrm{m}$, was placed at $12 \mathrm{~mm}$ from the tooth surface, with $400 \mathrm{~mJ}$ of energy/pulse and $4 \mathrm{~Hz}$ of frequency, yielding an energy density of $133.33 \mathrm{~J} / \mathrm{cm}^{2}$. Ablation was performed until the dimensions were reached. The depth of the preparation was constantly checked with a millimeter probe.

In both groups, part of the specimens received the adhesives as recommended by the manufacturers, whereas some modifications in the application technique were used for the other teeth, as follows:

For group 1, the adhesive systems were applied on 20 teeth following the manufacturer's instructions; the other 20 specimens were prepared with Er:YAG laser with low energy density $(60 \mathrm{~mJ} / 10 \mathrm{~Hz})$ on the entire cavity, followed by application of the same adhesive systems, except for the step of total acid-etching.

For group 2, after cavity preparation with laser, 20 specimens received the same adhesive systems as group 1, following the manufacturer's instructions, and the remaining 10 specimens received the Excite adhesive system without accomplishment of total acid-etching. There was no need to repeat the other subgroup because of utilization of the selfetching adhesive One Up (Flow Chart 1).

After application of the respective adhesive systems, the cavities were restored by insertion of the universal hybrid composite resin (Z250-3M/ESPE), shade A2, in two oblique increments, light-cured for 20 s each.

After completion of restorations, the teeth were immersed in distilled water, kept in a bacteriological oven at $37^{\circ} \mathrm{C}$ for 24 hours, then finished and polished with sequential Sof-Lex disks $(3 \mathrm{M})$, followed by thermocycling of the specimens, adding up to 800 cycles ( 30 seconds at $5^{\circ} \mathrm{C}$ and 30 seconds at $55^{\circ} \mathrm{C} \pm 2^{\circ} \mathrm{C}$ ), in a thermocycling machine (Ética Equipamentos Científicos).

Marginal microleakage was analyzed by the clearing technique described by TAY et $\mathrm{al}^{8}{ }^{8} 1995$ and modified by TORRES et al, ${ }^{9} 2003$, because it allows three-dimensional observation of tracer penetration. For that purpose, the region corresponding to $0.5 \mathrm{~mm}$ around the restoration margins was delineated with pencil, and the specimens were completely sealed, except for the delimited area, by application of three coats of nail polish. After drying, the specimens were immersed in distilled water, placed in a vacuum chamber and submitted to a negative atmosphere at 20 inch $\mathrm{Hg}$ for 5 minutes, in order to remove any entrapped air at the marginal gaps, by a compressor/aspirator (Dia Pump - Fanem Ltda) attached to a glass dome.

Afterwards, the specimens were not exposed to air anymore in order to avoid drying, and were submitted to the tracer element. The teeth were immersed in freshly prepared $50 \%$ silver nitrate aqueous solution at $50 \%$ for 24 hours in a dark environment. After this period, they were washed in tap distilled

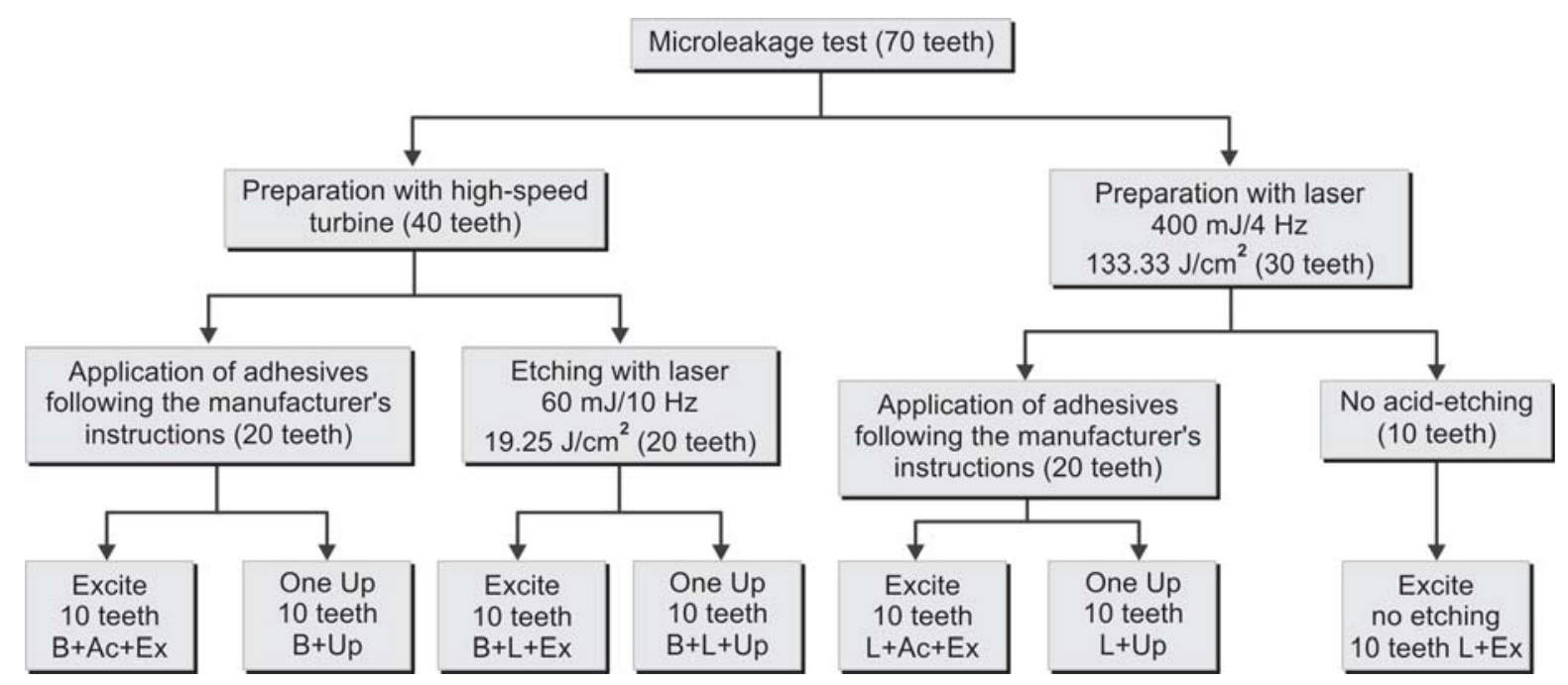

Flow Chart 1: Distribution of the specimens according to group and adhesive techniques employed 
Cavity Preparation with Er:YAG Laser or R otary Instruments: Investigation of the Composite Resin Restorations Interface

water for 10 minutes, immersed in developing solution (Kodak) and exposed to fluorescent light for 12 hours, followed by washing in tap water for 2 hours. The teeth were labeled to identify the respective groups, and the nail polish applied on the tooth surface was removed with a blade to enhance decalcification. Transverse sections were performed following the tooth long axis, at nearly $2 \mathrm{~mm}$ from the tooth-restoration interface, in mesiodistal direction with a sectioning machine for hard tissues and a diamond disk (Labcut - Extec).

Longitudinal sections were then performed on the mesial and distal aspects with a carborundum disk at high-speed, to separate the buccal aspect that contained the restoration, which were then submitted to the clearing technique.

For that purpose, the blocks containing the restorations were immersed in $6 \%$ hydrochloric acid aqueous solution for three days; the solution was shaken three times a day, and was daily changed in order to accelerate the demineralization process. The specimens were washed in tap water for 2 hours, followed by dehydration of the specimens by immersion in increasing ethanol concentrations $(70 \%, 80 \%, 95 \%)$ for 4 hours each, and finally three sequential immersions in absolute ethanol for each. After dehydration, the specimens were immersed in methyl salicylate $\left(\mathrm{C}_{8} \mathrm{H}_{8} \mathrm{O}_{3}\right)$ for the clearing technique, followed by additional immersions in new methyl salicylate until complete transparency of the specimen was achieved, allowing free threedimensional observation of the opaque remnant of the restoration as well as of the pathway of microleakage at the interface.

For evaluation of microleakage, all aspects of the restoration were analyzed by two calibrated examiners. During observation, the specimens were kept immersed in methyl salicylate in a Petri dish, and were taken to a light stereomicroscope with $25 \times$ magnification.

All cavity walls were evaluated for measurement of the degree of microleakage. The wall exhibiting the deepest dye leakage was used for quantification of microleakage. A linear measurement was then achieved in millimeters, from the cavosurface angle to the maximum point of penetration. The data achieved were submitted to statistical analysis by utilization of the one-way parametric analysis of variance (ANOVA) and Tukey test for multiple comparisons. A significance level of $5 \%$ was employed for all analyses.

\section{RESULTS}

The one-way parametric analysis of variance revealed a p-value of 0.00, indicating differences between the subgroups (Table 1).

Figure 1 demonstrates that the group submitted to cavity preparation with laser and acid-etching presented a greater degree of microleakage than the other groups. It also reveals that despite of the lack of statistically significant difference between the subgroups, except for the $(\mathrm{L}+\mathrm{Ac}+\mathrm{Ex})$, in the subgroups in which the self-etching adhesive was used, regardless of the equipment for cavity preparation (high-speed or laser), there is homogeneity of outcomes and tendency of lower degree of marginal microleakage. Figure 2 shows specimens with different degrees of microleakage by silver nitrate.

\section{DISCUSSION}

The hermetic sealing of restorations is the primary objective of dentistry, ${ }^{10}$ because only by this there may be long-lasting restorations with no pulp alterations.

The self-etching adhesives, which allow modification of the newly cut dentin surface and infiltrate into it, have been developed with a view to overcome these failures, maybe providing shorter treatment time and better adhesive efficiency. ${ }^{1}$

Utilization of the Er:YAG laser has been considered an effective instrument for cavity preparation. The laser is able to cut as high-speed turbines, stimulate the secondary dentin, have an antibacterial effect ${ }^{11,3}$ and may modify the dentin structure, improving the adhesion and consequently the sealing of restorations. ${ }^{12,21}$ According to Vissuri et al ${ }^{13} 1996$ and Groth et $\mathrm{al}^{14} 2001$, it is able to provide acceptable microretention for adhesive materials, roughening the dentin as the acid-etching.

The radiation with Er:YAG laser removes the smear layer of the dentin and exposes the dentinal tubules, ${ }^{2,15,16,5}$ which theoretically makes the surface more favorable to adhesion with the adhesive systems.

Another finding of investigations is that radiation with laser may make the tooth surface acid-resistant, and thus prevent secondary caries. ${ }^{4,16,21}$

Despite the effects of laser on the tooth structure, microleakage tests comparing conventional preparations with high-speed turbines and the Er:YAG laser did not demonstrate that it might be entirely replaced. ${ }^{2,5,6}$

In the present investigation, the clearing method allowed three-dimensional observation of dye penetration in the specimens, leaving no doubts as to the extension of microleakage (see Figs 2A to F), clarifying the comparisons between the variables proposed and revealing that, despite the variable intensities, microleakage always occurred.

Table 1 reveals that the cavity preparations performed with high-speed turbines or laser presented similar means of marginal leakage, i.e. similar performance, in agreement with the study of Yamada et $\mathrm{al}^{15} 2002$, Aranha et $\mathrm{al}^{4} 2005$, and different from

\begin{tabular}{|c|c|c|}
\hline Subgroups & Mean ( \pm standard deviation) & Groups \\
\hline $\mathrm{B}+\mathrm{L}+\mathrm{Up}$ & $0.43( \pm 0.39)$ & $A$ \\
\hline L+Up & $0.46( \pm 0.33)$ & A \\
\hline $\mathrm{B}+\mathrm{Up}$ & $0.53( \pm 0.35)$ & A \\
\hline$B+A c+E x$ & $0.64( \pm 0.53)$ & A \\
\hline $\mathrm{L}+\mathrm{Ex}$ & $0.74( \pm 0.65)$ & A \\
\hline$B+L+E x$ & $1.15( \pm 1.24)$ & $A$ \\
\hline$L+A c+E x$ & $2.43( \pm 1.21)$ & $\mathrm{B}$ \\
\hline
\end{tabular}




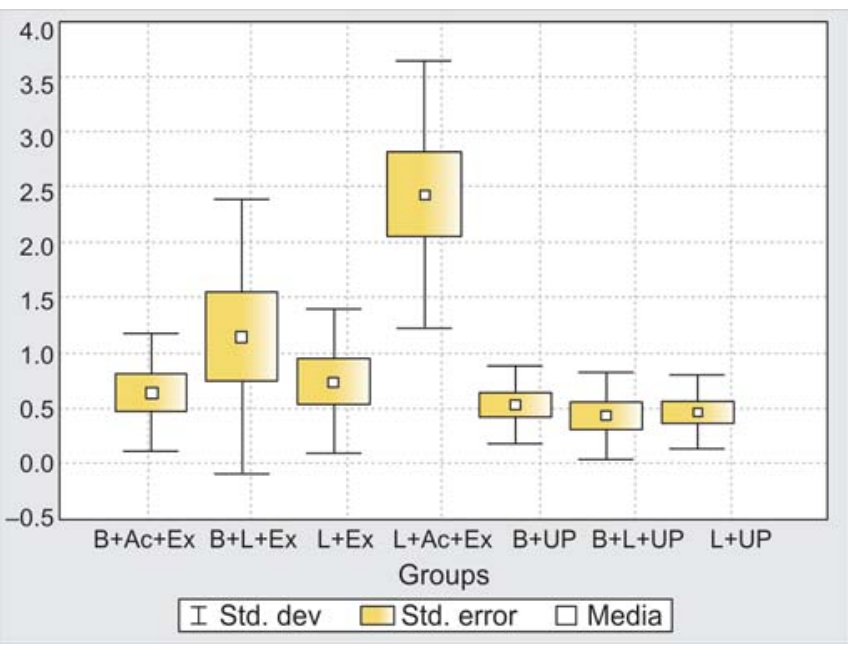

Fig. 1: Box and Whisker Plot diagram of the marginal microleakage in the study groups

others studies, ${ }^{2,5,6}$ which observed less leakage with the laser preparation.

When the cavity preparation with the high-speed turbine was associated with the surface laser preparation $(60 \mathrm{~mJ}$ and $10 \mathrm{~Hz}$ ), there was also no statistically significant difference compared to the acid-etching group. These results are in agreement with Ceballos et $\mathrm{al}^{2} 2001$. However, some studies consider that laser etching may improve the effectiveness of adhesion to enamel and dentin, ${ }^{13,21}$ reduction in marginal microleakage and increase the surface porosity. ${ }^{14}$

Martinez-Insua et $\mathrm{al}^{17} 2000$, conducted bond strength tests and found that acid-etching was significantly better than that performed with the Er:YAG laser, since the enamel and dentin surfaces prepared with laser exhibited extensive cracking, thereby being unfavorable to adhesion.
It was also observed that the adhesive systems, despite the lack of statistically significant differences in the means of marginal leakage, presented a more homogeneous performance when the self-etching system was employed, as demonstrated in Figure 1 (Box-Plot). There was less variation of the values achieved, and the mean was similar for all three study groups (B+Up; B+L+Up; L+Up).

These results may be assigned to the fact that self-etching systems present a different mechanism of adhesion compared to the conventional, since they yield demineralization of the tooth surface and concomitant infiltration of resin monomers in a single application. No need of previous demineralizing treatment eliminates the need of humidity control, forming a uniformly infiltrated hybrid layer, yet with a small thickness; smear layer particles may be found entrapped in the hybrid layer. $^{5,21}$

On the other hand, when used the self-etching system Etch and Prime 3.0 and it was observed the largest values of marginal leakage, especially at the cervical margins of the cavity. ${ }^{18}$

The cavity preparations with laser submitted to etching with $37 \%$ phosphoric acid and conventional adhesive system ( $\mathrm{L}+$ Ac+Ex) displayed high microleakage values, with statistical significance compared to the other study groups, in agreement with Ceballos et $\mathrm{al}^{2} 2001$. This suggests that laser radiation at $400 \mathrm{~mJ}$ with $4 \mathrm{~Hz}$ of frequency yields alterations in the tooth structure, as also observed in another study, ${ }^{14}$ which found microcracks on the surface, increased porosity and also irreversible damages to the pulp when the energy is close to $500 \mathrm{~mJ}$. In an investigation conducted by Setien et al ${ }^{19} 2001$, specimens prepared with the Er:YAG laser and etched acids demonstrated absence of the normal pattern of collagen fibers under SEM. The fibers appeared, collapsed and melted,
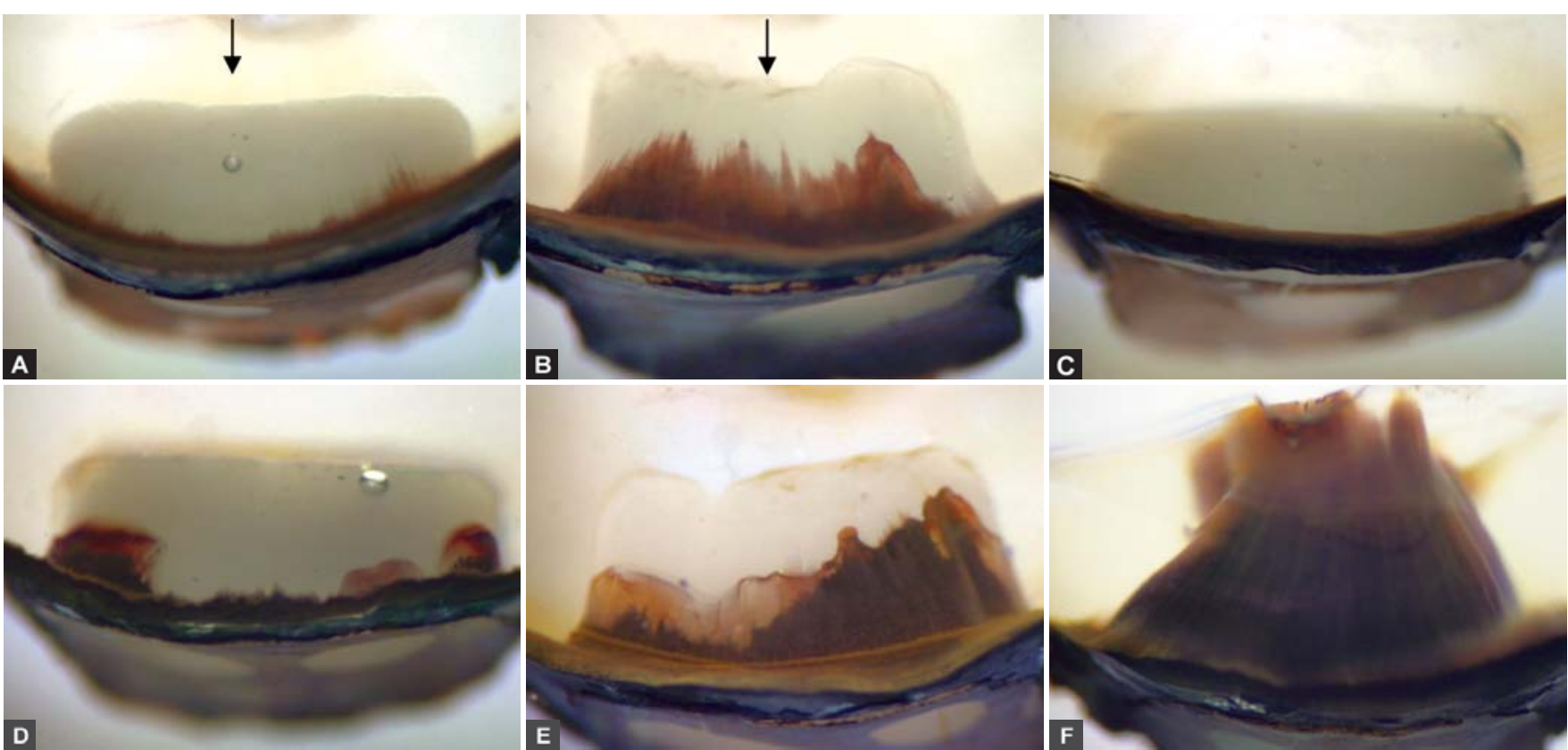

Figs $2 \mathrm{~A}$ to $\mathrm{F}$ : Microleakage by silver nitrate: (A) cavity preparation performed with diamond bur, note plane and regular axial wall; (B) cavity preparation performed with Er:YAG laser, revealing irregular axial wall; (C) specimen with no occurrence of marginal leakage (O); (D) specimen with moderate marginal leakage $(1.6 \mathrm{~mm})$; $(E)$ specimen with severe marginal leakage $(2.4 \mathrm{~mm})$; $(F)$ specimen with total marginal leakage, penetrating into the dentin toward the pulp 
Cavity Preparation with Er:YAG Laser or R otary Instruments: Investigation of the Composite Resin Restorations Interface

compared to other specimens prepared with burs and etched with acid. It is possible that exposure to the high temperatures of laser, even for short periods, may cause denaturation of the collagen fibers. According to Roebuck et $\mathrm{al}^{11} 2000$, the energy employed for cavity preparation should be $200 \mathrm{~mJ}$ for the enamel and $300 \mathrm{~mJ}$ for dentin, and for finishing it should be $100 \mathrm{~mJ}$, since these energies achieved the lowest values of marginal microleakage.

Associating this to etching with phosphoric acid, it might be assumed that the collagen may have undergone denaturation, impairing the sealing.

Since the larger the acid penetration, the larger will be the area of dentin demineralization with greater difficulty of penetration of resin monomers, it may be concluded that the association would be unfavorable, since there would be a nonimpregnated area of collagen susceptible to greater microleakage. In the long-term, this area not interpenetrated by the resin monomers would be susceptible to hydrolysis, leakage, discoloration, secondary caries and pulp alterations. ${ }^{20}$

However, some studies, ${ }^{3,4,21}$ revealed a high degree of microleakage when the Er:YAG laser was employed for cavity preparation; when it was associated with acid-etching, the values of marginal microleakage were similar to those of the group prepared with high-speed turbine and acid-etching.

\section{CONCLUSIONS}

- Preparations performed with high-speed turbines and Er:YAG laser presented the same performance.

- Preparations with Er:YAG laser submitted to acid-etching and conventional adhesive system presented high values of marginal microleakage, with statistical significance.

- Conventional and self-etching adhesive systems displayed the same performance as to marginal microleakage.

\section{REFERENCES}

1. Perdigão J. New developments in dental adhesion. Dent Clin North Am Apr 2007;51(2):333-57.

2. Ceballos L, Osorio R, Toledano M, Marshall GW. Microleakage of composite restorations after acid or Er-YAG laser cavity treatments. Dental Materials 2001;17(4):340-46.

3. Corona SAM, Borsatto MC, Pécora JD, De Sá Rocha RAS, Ramos TS, Dibb RGP. Assessing microleakage of different class $\mathrm{V}$ restorations after Er:YAG laser and bur preparation. J Oral Rehabil 2003;30:1008-14.

4. Aranha AC, Turbino ML, Powell GL, Eduardo CP. Assessing microleakage of class $\mathrm{V}$ composite restorations after Er:YAG laser and bur preparation. Lasers Surg Med 2005;37(2): 172-77.

5. Bertrand MF, Semez G, Leforestier E, Muller-Bolla M, Nammour S, Rocca JP. Er:YAG laser preparation and composite resin bonding with a single-component adhesive system:
Relationship between shear bond strength and microleakage. Lasers Sugr Med 2006;38(6):615-23.

6. Chinelatti MA, Ramos RP, Chimello DT, Corona SA, Pécora JD, Dibb RG. Influence of Er:YAG laser on cavity preparation and surface treatment in microleakage of composite resin restorations. Photomed Laser Surg 2006;24(2):214-18.

7. Tonami K. Effect of storage on tensile strength of bovine dentin. J Dent Res 1996 75(sp. iss.), 288.

8. Tay FR, Pang KM, Gwinett AJ, Wei SH. A method for microleakage evaluation along the dentin/restorative interface. Am J Dent 1995;8(2):105-08.

9. Torres CRG, Araujo MAM, Torres ACM. Effects of dentin collagen removal on microleakage of bonded restorations. J Adhes Dent 2003;5:1-12.

10. Feuerstein O, Matalon S, Slutzky H, Weiss EI. Antibacterial properties of self-etching dental adhesive systems. J Am Dent Assoc Mar 2007;138(3):349-54; quiz 396-98.

11. Roebuck EM, Saunders WP, Whitters CJ. Influence of Erbium: YAG laser energies on the microleakage of Class V resin-based composite restorations. Am J Dent 2000;13(5):280-84.

12. Kameyama A, Koga H, Takizawa M, Takaesu Y, Hiray Y. Effect of Er:YAG laser irradiation on acid resístance to bovine dentin in vitro. Bull Tokyo Dent Coll 2000;14(2):43-48.

13. Visuri SR, Gilbert JL, Wright DD, Wigdor HA, Walsh JR, JT. Shear strengths of composite bonded to Er:YAG laser prepared dentin. J Dent Res 1996;75:599-605.

14. Groth EB, Mercer CE, Anderson P. Microtomographic analysis of subsurface enamel and dentine following Er:YAG laser and acid-etching. Eur J Prosthod Restor Dent 2001;9(2):73-79.

15. Yamada $Y$, Hossain M, Nakamura Y, Murakami Y, Matsumoto K. Microleakage of composite resin restoration in cavities prepared by Er:YAG laser irradiation in primary teeth. Eur J Paediatr Dent Mar 2002;3(1):39-45.

16. Delme KI, Deman PJ, DE Moor RJ. Microleakage of class V resin composite restorations after conventional and Er:YAG laser preparation. J Oral Rehabil 2005;32(9):676-85.

17. Martinez-Insua A, et al. Differences in bonding to acid-etched or Er:YAG laser-treated enamel and dentin surfaces. J Prosthet Dent 2000;84(3):280-88.

18. Dibb R GP, Corona SAM, Borsatto MC, Ferreira KC, Ramos RP, Pecora JD. Assessing microleakage on class V composite resin restoration after Er:YAG laser preparation varying the adhesive systems. J Clin Laser Med and Surg 2002;20(3): 129-33.

19. Setien VJ, Cobb DS, Denehy GE, Vargas MA. Cavity preparation devices: Effect on microleakage of class $\mathrm{V}$ resinbased composite restorations. Am J Dent 2001;4(3):157-62.

20. Araujo RM, Eduardo CP, Duarte Junior SL, Araujo MA, Loffredo LC. Microleakage and nanoleakage: Influence of laser in cavity preparation and dentin pretreatment. J Clin Laser Med Surg Dec 2001;19(6):325-32.

21. Kohara EK, Hossain M, Kimura Y, Matsumoto K, Inoue M, Sasa R. Morphological and microleakage studies of the cavities prepared by Er:YAG laser irradiation in primary teeth. J Clin Laser Med and Surg 2002;20(3):141-47. 